Article

\title{
Enhanced Anaerobic Mixed Culture Fermentation with Anion-Exchange Resin for Caproate Production
}

\author{
Jiangnan $\mathrm{Yu}^{1}$, Jialin Liao ${ }^{1}$, Zhenxing Huang ${ }^{1,2,3, *}$, Peng $\mathrm{Wu}^{4}$, Mingxing Zhao ${ }^{1,2}$, Chunmei Liu ${ }^{1}$ \\ and Wenquan Ruan 1,2,3,* \\ 1 Jiangsu Key Laboratory of Anaerobic Biotechnology, School of Environment and Civil Engineering, \\ Jiangnan University, Wuxi 214122, China \\ 2 Jiangsu Collaborative Innovation Center of Technology and Material of Water Treatment, \\ Suzhou 215011, China \\ 3 Jiangsu Engineering Laboratory for Biomass Energy and Carbon Reduction Technology, Jiangnan University, \\ Wuxi 214122, China \\ 4 School of Environmental Science and Engineering, Suzhou University of Science and Technology, \\ Suzhou 215009, China \\ * $\quad$ Correspondence: biogashuang@jiangnan.edu.cn (Z.H.); wqruanjn@gmail.com (W.R.); \\ Tel.: +86-510-8519-7091 (Z.H. \& W.R.)
}

Received: 15 May 2019; Accepted: 20 June 2019; Published: 1 July 2019

\begin{abstract}
The bioproduction of caproate from organic waste by anaerobic mixed culture is a very attractive technology for upgrading low-grade biomass to a high-value resource. However, the caproate production process is markedly restricted by the feedback inhibition of caproate. In this study, four types of anion-exchange resin were investigated for their enhancing capability in caproate fermentation of anaerobic mixed culture. The strong base anion-exchange resin D201 showed the highest adsorption capacity (62 mg/g), selectivity (7.50), and desorption efficiency (88.2\%) for caproate among the test resins. Subsequently, the optimal desorption temperature and $\mathrm{NaOH}$ concentration of eluent for D201 were determined. The adsorption and desorption efficiency of D201 remained stable during eight rounds of the adsorption-desorption cycle, indicating a satisfactory reusability of D201. Finally, performances of caproate fermentation with and without resin adsorption for carboxylate were evaluated. The results demonstrated that the final concentration of caproate was improved from $12.43 \pm 0.29 \mathrm{~g} / \mathrm{L}$ (without adsorption) to $17.30 \pm 0.13 \mathrm{~g} / \mathrm{L}$ (with adsorption) and the maximum caproate production rate was improved from $0.60 \pm 0.01 \mathrm{~g} / \mathrm{L} / \mathrm{d}$ to $2.03 \pm 0.02 \mathrm{~g} / \mathrm{L} / \mathrm{d}$. In the group with adsorption, the cumulative caproate production was increased to $29.10 \pm 0.33 \mathrm{~g} / \mathrm{L}$ broth, which was $134 \%$ higher than that of the control group. Therefore, this study provides effective approaches to enhance caproate production.
\end{abstract}

Keywords: anaerobic mixed culture; caproate fermentation; adsorption process; enhanced performance

\section{Introduction}

Caproate is a high-density energy carrier and a high-value added chemical which is applicable in a variety of industries, e.g., petrochemical, pharmaceutical, and food manufacturing [1,2]. The production of caproate from waste stream material can simultaneously achieve the recovery of high-value biological products and waste reduction [1,2]. Thus, studies of this technology have recently been intensively reported [3-5]. Caproate production is a two-stage fermentation process [6]. Firstly, the organic waste is hydrolyzed and acidified in the acidification stage to produce short chain carboxylic acids (SCCAs). Subsequently, in the caproate fermentation stage, SCCAs, together with the electron donor, such as ethanol, are utilized by anaerobic mixed culture to biosynthesize caproate [4,5]. With a longer carbon chain tail, caproate demonstrates higher lipophilicity and better recovery potential 
than SCCAs [7]. However, as a double-edged sword, caproate can also penetrate cell membranes more easily than SCCAs and poses a critical threat [8]. Product inhibition of caproate is thus distinctly exacerbated [9]. The inhibition of carboxylic acid can be alleviated by neutral $\mathrm{pH}$ conditions [10]. The dissociated form of carboxylate is formed more in neutral $\mathrm{pH}$ conditions, which therefore results in less inhibition. Nevertheless, recent research indicates that even the dissociated state of caproate still shows considerable toxicity to microbes $[9,11]$. Thus, in order to achieve higher caproate production, monitoring feedback inhibition is an inevitable challenge.

Recently, Roghair et al. [12] and Grootscholten et al. [5] reported that with more biomass sustained in reactors to alleviate the inhibition, enhanced caproate production was achieved. Liu et al. reported that the toxicity of caproate could be alleviated by a local alkaline $\mathrm{pH}$ created by exogenous biochar [11]. Roghair et al. attributed an improvement of caproate tolerance to the evolution of adaptive mixed cultures [9]. These studies aimed to enhance tolerance to caproate toxicity using different approaches, however, caproate still existed in the fermentation broth. In order to fundamentally solve the feedback toxicity problem and improve product recovery potential, a further separation process is needed.

The separation/recovery process reported in carboxylic fermentation mainly includes organic solvent extraction [13], electrodialysis [14,15], and resin adsorption [16-18]. The organic solvent extraction is based on the difference of lipophilicity between products and substrate molecules [13]. Choi et al. applied diphasic organic extraction in caproate fermentation of Megasphaera elsdenii NCIMB 702410 to improve caproate production. However, cell lysis caused by the direct contact between cells and the organic extraction solvent was reported as the side effect of this approach [13]. Ge et al. [19] applied an inline membrane-extraction system in a medium chain carboxylic acid production reactor. In this system, a membrane separated organic extraction solution and the fermentation broth so that direct contact between the organic solvent and the biomass was avoided. However, the inline extraction system is capital intensive [20], which increases system complexity and limits its application.

Electrodialysis is applied to concentrate the carboxylate in the fermentation process [14]. However, this approach is based on the difference between the electrical properties of the substrate and product [21]. In the caproate mixed culture production, the substrate SCCAs and produced caproate are both monovalent anions. Thus, the selectivity for the target carboxylate is poor, especially for caproate [22].

Anion exchange processes are used widely in fermentation $[23,24]$. Rebecchi et al. reported the separation/recovery of volatile fatty acids from actual grape acidification broth, thus enhancing the acidification performance [25]. Fargues et al. reported a comparison of the performance of different resins by applying anion-exchange resin for carboxylate removal, detoxification, and purification of beet distillery [26]. Anion-exchange resin adsorption is based on physical absorption and anion exchange [16]. It is interesting that the affinity of carboxylic acid to resin increases as the hydrocarbon chain increases $[16,23,25]$. It might be possible to use this selectivity to improve resin adsorption in caproate fermentation. Recent studies on the use of resin in caproate fermentation are rare. To the best of our knowledge, the only such study was reported by Roddick et al. [10]. In their study, resin was applied in order to extract the products from a pure culture of Megasphaera elsdenii. However, the application of anion-exchange resin has not yet been reported in a mixed culture caproate fermentation system.

Hence, in order to select the optimal resin for the enhancement of mixed culture caproate production, in this study, the application potential of different resins was firstly evaluated in static adsorption using simulated fermentation broth. Subsequently, using the selected resin, optimization for desorption efficiency and reusability of the resin were evaluated. Following this, the adsorption process was coupled with a fed-batch fermentation reactor to enhance caproate production. By comparing the production rate, the highest caproate concentration, and the cumulative caproate production, the enhancement of the fermentation performance was evaluated. 


\section{Materials and Methods}

\subsection{Experimental Materials for Resin Screening and Fermentation}

The anion-exchange resins used in this study were D201, D202, D301R, and D301G, which were all purchased from the Chemical Plant of Nankai University (Tianjin, China). The physiochemical properties of resins are shown in Table 1. Before screening, the resins were pretreated under the protocol provided by the manufacturer, which is as follows: (1) Soak the resins in deionized water for $24 \mathrm{~h}$; (2) successively soak the wet resin in $1 \mathrm{M} \mathrm{NaOH}$ solution, $1 \mathrm{M} \mathrm{HCl}$ solution, and $1 \mathrm{M} \mathrm{NaOH}$ solution, each for $24 \mathrm{~h}$; (3) flush the resin using deionized water until the effluent reaches a neutral $\mathrm{pH}$.

Table 1. Physicochemical properties of the resin.

\begin{tabular}{|c|c|c|c|c|}
\hline \multirow{2}{*}{ Property } & \multicolumn{4}{|c|}{ Resin } \\
\hline & D201 & D202 & D301R & D301G \\
\hline Type & Strongly basic & Strongly basic II & Weakly basic & Weakly basic \\
\hline Matrix & $\begin{array}{l}\text { Styrene-divinylbenzene } \\
\text { (DVB) }\end{array}$ & Styrene-DVB & Styrene-DVB & Styrene-DVB \\
\hline Functional group & $\begin{array}{l}\text { Quaternary } \\
\text { ammonium }\end{array}$ & $\begin{array}{c}\text { Dimethyl } \\
\text { ethanolamine }\end{array}$ & Tertiary amine & Tertiary amine \\
\hline Ion form as shipped & $\mathrm{Cl}^{-}$ & $\mathrm{Cl}^{-}$ & $\mathrm{Cl}^{-}$ & $\mathrm{Cl}^{-}$ \\
\hline Grain diameter (mm) & $0.4-0.7$ & $0.42-0.6$ & $0.4-0.7$ & $0.65-0.72$ \\
\hline
\end{tabular}

The adsorption temperature was maintained at $30 \pm 0.5^{\circ} \mathrm{C}$ and the composition per $\mathrm{L}$ of the simulated fermentation broth included $3 \mathrm{~g}$ acetate, $3 \mathrm{~g}$ butyrate, and $10 \mathrm{~g}$ caproate. The $\mathrm{pH}$ was adjusted to $7.0 \pm 0.1$ using $3 \mathrm{M} \mathrm{NaOH}$ solution.

The acidification supernate used for caproate fermentation was obtained from effluent of an acidification batch reactor treating fruit and vegetable waste. The effluent was centrifuged at $13,523 \times g$ for $5 \mathrm{~min}$ to obtain the supernate. The main liquid components were acetate $(3.55 \pm 0.05 \mathrm{~g} / \mathrm{L})$, butyrate $(3.35 \pm 0.11 \mathrm{~g} / \mathrm{L})$, and ethanol $(0.79 \pm 0.17 \mathrm{~g} / \mathrm{L})$. The inoculum for caproate fermentation was obtained from a well-operated anaerobic digester treating starch syrup wastewater (Chaoke Food Co., Ltd., Wuxi, China). Before inoculation, the sludge was pretreated in $121{ }^{\circ} \mathrm{C}$ for 15 min to suppress methanogens. The concentration of total solid (TS) and volatile solid (VS) in the inoculum were $12.3 \%$ $\pm 0.9 \%$ and $10.6 \% \pm 0.7 \%$, respectively. An anion-exchange resin column (POM series, Xiamei Ltd. Inc., Shanghai, China) was used for the coupled caproate fermentation, which was made of polymer glass $\left(16 \times 300 \mathrm{~mm}^{2}\right)$. Before the adsorption operation, the column was filled with $40 \mathrm{~g}$ of pretreated resin. In order to avoid short-circuiting of the effluent and resin washout, sieves with 500-mesh were equipped in the top and bottom of the column. The column was connected to the bioreactor by silicon tubes. The anion exchange operation used in coupled fermentation was conducted under specific conditions described in Section 2.3. For each operation, the effluent pump and reflux pump (YZ1515, Longer Precision Pump Co., Ltd., Baoding, China) were simultaneously operated at a flow rate of $5 \mathrm{~mL} / \mathrm{min}$ for $3 \mathrm{~h}$.

\subsection{Comparison and Selection of Optimal Resin}

The screening of the four anion-exchange resins was based on the caproate adsorption capacity $\left(Q_{\text {caproate }}\right)$, selectivity $\left(R_{S}\right)$, and desorption efficiency $\left(Y_{\text {desorption }}\right)$. To determine the performance of each resin, an adsorption/desorption equilibrium was reached in a $250 \mathrm{~mL}$ flask using a magnetic stirrer (MS-H280-Pro, DLAB Scientific Co., Ltd., Beijing, China) at $200 \mathrm{rpm}$ in static adsorption mode. The adsorption and desorption tests were carried out as follows. (1) For the adsorption tests, $5 \mathrm{~g}$ of pretreated resin was added to $100 \mathrm{~mL}$ simulated fermentation broth. (2) For the desorption tests, $5 \mathrm{~g}$ of carboxylate-saturated resin was added to $100 \mathrm{~mL}$ of $1 \mathrm{M} \mathrm{NaOH}$ eluent solution. The fermentation temperature was maintained at $30^{\circ} \mathrm{C}$. Liquid samples were taken from the flasks 
and analyzed to evaluate the adsorption/desorption performance until an adsorption/desorption equilibrium was reached.

The $Q_{\text {carboxylate }}$ in $\mathrm{mg} / \mathrm{g}$ at equilibrium was calculated with Equation (1), where $\mathrm{M}$ is the weight of pretreated resin in $g$ and $\mathrm{V}_{\mathrm{a}}$ is the volume in $\mathrm{L}$ of the simulated fermentation broth. $\mathrm{C}_{0}$ and $\mathrm{C}_{\mathrm{e}}$ are the concentrations in $\mathrm{mg} / \mathrm{L}$ of carboxylate in the flasks initially and at the adsorption equilibrium, respectively.

$$
\mathrm{Q}_{\text {carboxylate }}=\frac{\left(\mathrm{C}_{0}-\mathrm{C}_{\mathrm{e}}\right) \times \mathrm{V}_{\mathrm{a}}}{\mathrm{M}}
$$

The $R_{\mathrm{s}}$ was determined with Equation (2), where $Q_{\text {acetate, }} \mathrm{Q}_{\text {butyrate, }}$ and $\mathrm{Q}_{\text {caproate }}$ are the adsorption capacities of acetate, butyrate, and caproate, respectively.

$$
\mathrm{R}_{\mathrm{s}}=\frac{\mathrm{Q}_{\text {caproate }}}{\mathrm{Q}_{\text {acetate }}+\mathrm{Q}_{\text {butyrate }}}
$$

The distribution of carboxylate in the fermentation broth $(C / A+B)$ was characterized using Equation (3), where $C_{\text {caproate, }} C_{\text {acetate, }}$ and $C_{\text {butyrate }}$ are the concentrations in $\mathrm{g} / \mathrm{L}$ of caproate, acetate, and butyrate, respectively, in the simulated or actual fermentation broth.

$$
\mathrm{C} / \mathrm{A}+\mathrm{B}=\frac{\mathrm{C}_{\text {caproate }}}{\mathrm{C}_{\text {butyra }}+\mathrm{C}_{\text {acetate }}}
$$

The desorption efficiency of resins $\left(\mathrm{Y}_{\text {desorption }}^{\text {carboxyle }}\right.$, in \%) was calculated with Equation (4), where $C_{\mathrm{de}}$ and $\mathrm{C}_{\mathrm{d} 0}$ are the concentrations in $\mathrm{mg} / \mathrm{L}$ of carboxylate in the eluent detected at the equilibrium and start of the experiments, respectively, and $V_{d}$ is the volume of eluent in $\mathrm{L}$.

$$
\mathrm{Y}_{\text {desorption }}^{\text {carboxlate }}=\frac{\left(\mathrm{C}_{\mathrm{de}}-\mathrm{C}_{\mathrm{d} 0}\right) \times \mathrm{V}_{\mathrm{d}}}{\left(\mathrm{C}_{0}-\mathrm{C}_{\mathrm{e}}\right) \times \mathrm{V}_{\mathrm{a}}}
$$

After the evaluation of the resin performance, the optimal resin in the carboxylate-saturated state was selected or chosen. The optimal elution temperature was investigated at $5,20,30$, and $40^{\circ} \mathrm{C}$. At the determined optimal temperature, the optimal $\mathrm{NaOH}$ concentration of the eluent was tested at $0.5,1.5$, 2.0 , and $2.5 \mathrm{M}$.

Based on the optimal elution temperature and concentration of $\mathrm{NaOH}$, eight consecutive adsorption-desorption cycles were performed to evaluate the reusability of resin.

In order to compare and evaluate the enhancement of caproate production, Student's t test was analyzed with SPSS software (Version 10.0).

\subsection{Enhancement of Caproate Fermentation with Anion-Exchange Resin Adsorption}

The evaluations of the caproate fermentation performance with or without adsorption were conducted in bioreactors with $0.8 \mathrm{~L}$ working volume. Fermentation $\mathrm{pH}$ and temperature were controlled at $7.0 \pm 0.2$ and $30.0 \pm 0.5^{\circ} \mathrm{C}$. The initial concentration of ethanol was maintained at $17.06 \pm 0.04 \mathrm{~g} / \mathrm{L}$. The concentration of inoculum used was $18.1 \pm 0.5 \mathrm{~g}-\mathrm{VS} / \mathrm{L}$. Reactors with or without adsorption were anaerobically started-up with $\mathrm{N}_{2}$ flushing for $10 \mathrm{~min}$. During the operation, liquid samples were regularly taken for ethanol and carboxylate analyses. In order to maintain sufficient ethanol levels, once the ethanol concentration dropped below $4 \mathrm{~g} / \mathrm{L}$, it was readjusted to $16.1 \pm 0.8 \mathrm{~g} / \mathrm{L}$; when the acetate concentration fell below $1 \mathrm{~g} / \mathrm{L}$, it was adjusted to $3 \pm 0.1 \mathrm{~g} / \mathrm{L}$.

For the resin adsorption-coupled bioreactor, resin exchange was carried out on the 67th, 80th, 89th, and 120th days to remove the caproate from the fermentation broth. The anion exchange was performed using the stepwise removal of caproate for about $3.0 \mathrm{~g} / \mathrm{L}$ in each adsorption, instead of adsorbing all of the caproate in a single step. Thus, the maximum allowable caproate concentration for production performance recovery was estimated. 
After adsorption, desorption was carried out for resin regeneration. The protocol of desorption was described as above. The schematic diagram of the reactors is shown in Figure 1.

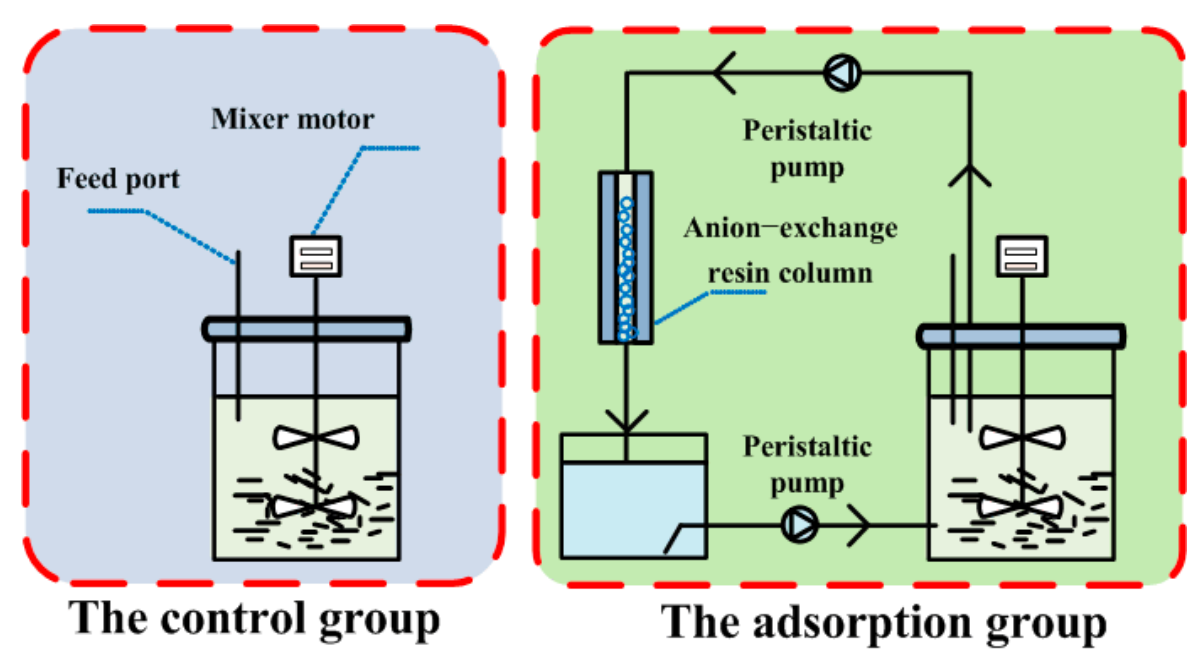

Figure 1. The schematic diagram of the control group and the adsorption group reactors.

\subsection{Chemical Analyses}

The total solid (TS) and volatile solid (VS) were measured according to the standard method [27]. For the carboxylate and ethanol measurements, gas chromatography (GC-2010 plus, Shimadzu, Kyoto, Japan) was used. Before analysis, the liquid sample was pretreated with $12,000 \times g$ centrifugation for $5 \mathrm{~min}$ and $0.45 \mu \mathrm{m}$ membrane filtration. The filtrate was then diluted with $3 \mathrm{M}$ phosphoric acid solution at a ratio of 1:1 to keep the $\mathrm{pH}$ below 3. Then the diluted filtrate was injected by AOC-20i auto-sampler with a split ratio of 50:1. The carrier gas was $\mathrm{N}_{2}$. The injection port and flame-ionization detector temperature were both $250{ }^{\circ} \mathrm{C}$. The column temperature increased from 70 to $210{ }^{\circ} \mathrm{C}$ at $15^{\circ} \mathrm{C} / \mathrm{min}$ ramp and the chromatographic column was a $30 \mathrm{~m} \times 0.25 \mathrm{~mm} \times 0.25 \mu \mathrm{m}$ capillary column (InterCap FFAP, SGLC, Shanghai, China).

\section{Results and Discussion}

\subsection{Optimal Resin for Enhancement of Caproate Production}

The adsorption performances of resins are shown in Figure 2. The highest caproate adsorption capacity of $62.0 \mathrm{mg} / \mathrm{g}$ was achieved by resin D201, which was $20.5 \%, 88.5 \%$, and $70.6 \%$ higher than the capabilities of resins D202, D301R, and D301G, respectively. Furthermore, the strong base anion-exchange resin (SBAER), D201, and D202 showed higher capacities than the weak base anion-exchange resin (WBAER), D301R, and D301G. The anion-exchange capacity is determined by the formation of the ionic bond between the electronegative carboxylic group in the broth and the electropositive functional group in the resin [25], even though the WBAER has a higher theoretical adsorption capacity than the SBAER. The functional groups of WBAERs (including primary, secondary, and tertiary amines) are less protonated at in higher $\mathrm{pH}$ conditions, whereas the functional groups of SBAERs (quaternary ammonium) are permanently electropositive [25]. Khor et al. reported that in neutral $\mathrm{pH}$ conditions, the SBAER showed a higher anion-exchange capacity [28] and Lopez-Garzon et al. reported the anion-exchange capacity of the WBAER declined significantly as the $\mathrm{pH}$ increased from the $\mathrm{p} K_{\mathrm{a}}$ of carboxylic acid to a neutral $\mathrm{pH}[29]$. 


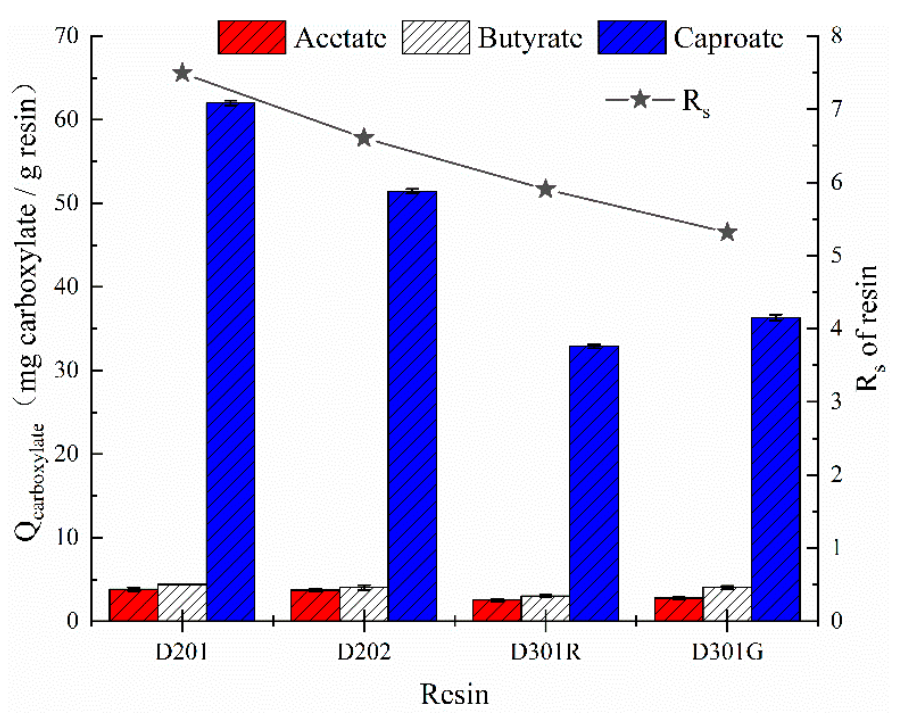

Figure 2. The adsorption capacity $\left(Q_{\text {carboxylate }}\right)$ and selectivity $\left(R_{s}\right)$ of resin D201, D202, D301R, and D301G in the simulated fermentation broth. The differences in physicochemical properties between resins are listed in Table 1 . The reaction condition is maintained at $30 \pm 0.5^{\circ} \mathrm{C}$ and $\mathrm{pH} 7 \pm 0.2$. Numerical results are the averages with standard deviations of triplicate experiments.

The $R_{\mathrm{s}}$ values of resins D201, D202, D301R, and D301G were 7.50, 6.61, 5.91, and 5.32, respectively. D201 showed the highest selectivity, which was $13.5 \%, 27.0 \%$, and $41.0 \%$ higher than that of D202, D301R, and D301G, respectively. The C/A + B value in the simulated fermentation broth was 1.67, which was less than the $R_{S}$ values of all resins. This finding indicated that caproate was better adsorbed than acetate and butyrate. Rebecchi et al. [25] and Khor et al. [28] also found this trend and speculated that physical adsorption was involved [28], as the octanol/water partition coefficient $\left(\mathrm{K}_{\mathrm{ow}}\right)$ value of caproate was at least 10 times higher than that of acetate or butyrate. Chu et al. attributed this selectivity to the hydration difference among carboxylates [30]. Kanazawa et al. reported that physical adsorption and anion exchange were simultaneously functional [23]. Moreover, da Silva et al. elucidated that the anion-exchange selectivity was the dominant factor; as a carboxylic acid with a longer hydrocarbon chain has lower acidity, in return, the conjugate base has stronger electronegativity. Thus, a carboxylate with a longer hydrocarbon chain tail would be better adsorbed by the resin [16]. These different features of caproate benefited its selective removal/recovery from the fermentation broth.

The desorption rate of caproate from different resins (Figure 3) was also an indicator to determine the resin performance. The results shown in Figure 3A suggest that the desorption efficiency of D201 reached $88.2 \%$ and was higher than that of other resins. Based on the overall comparison (Figure 3B), D201 was the optimal resin; this was supported by a significantly high adsorption capacity $(p<0.01)$, high desorption efficiency $(p<0.01)$, and high selectivity for caproate $(p<0.01)$. These results ascertain that D201 would be a potential exchange resin for caproate production. However, the desorption efficiency of caproate from this resin $(88.2 \%)$ was unsatisfied and yet required further improvements. 

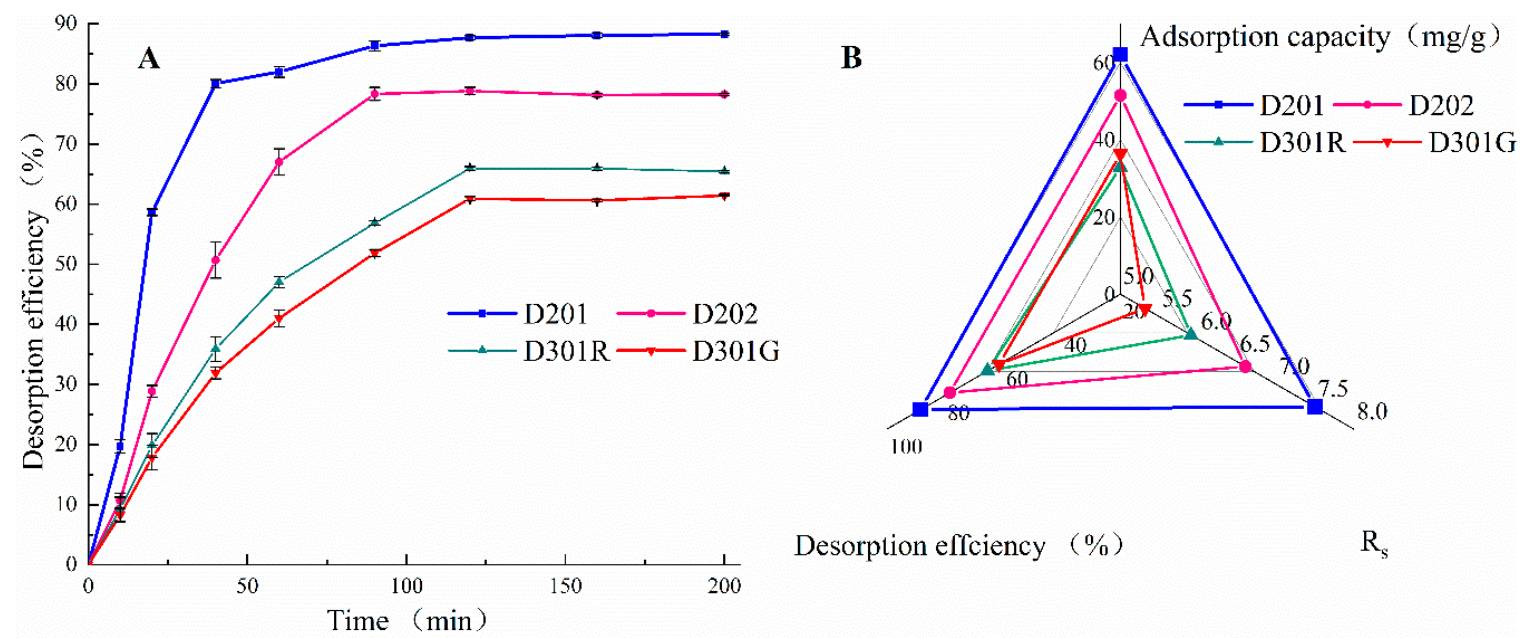

Figure 3. (A) The desorption efficiency and (B) overall performance of different resins (D201, D202, D301R, and D301G) in the simulated fermentation broth. The results present with averages and standard deviations of three parallel experiments. The indicators of the resin performance in (B) comprise of adsorption capacity, desorption efficiency, and selectivity (Rs).

\subsection{Optimal Desorption Condition and Reusability of D201}

It has been reported that temperature and elution solution are the determining factors for desorption efficiency in organic acid production [16,31]. The anion exchange is an exothermic process, hence, low temperature might contribute to a better performance. However, another parameter influencing anion exchange, e.g., anion diffusion, depends on temperature increment [16,31]. Researchers suggested also that an alkaline solution would increase elution efficiency [31]. However, over-concentrated alkaline eluent could not increase the efficiency further; on the contrary, it could increase the cost. Thus, we investigated the elution efficiency of carboxylate from the resin D201 under varying temperatures and with different concentrations of $\mathrm{NaOH}$ in eluent (Table 2). The elution efficiency at $5{ }^{\circ} \mathrm{C}$ was relatively low, compared to that at higher temperature $\left(20-40^{\circ} \mathrm{C}\right)$. The average desorption efficiencies at $20-40{ }^{\circ} \mathrm{C}$ of acetate, butyrate, and caproate were $95.97 \% \pm 0.92 \%, 86.93 \% \pm 0.81 \%$, and $88.61 \% \pm 0.43$, respectively. Although a relatively high desorption efficiency of carboxylate was observed at $20^{\circ} \mathrm{C}$, the desorption efficiencies within the temperature range of $20-40{ }^{\circ} \mathrm{C}$ were slightly different $(<1 \%)$. Furthermore, as the simulated fermentation broth was at $30^{\circ} \mathrm{C}$, maintaining elution at this temperature would achieve acceptable desorption efficiency without system complexity of heating or cooling.

Table 2. The optimization of elution temperature and eluent concentration.

\begin{tabular}{ccccc}
\hline \multirow{2}{*}{ Elution Factor } & & \multicolumn{3}{c}{${ }^{\mathrm{c}}$ Desorption Effeciency } \\
\cline { 2 - 5 } & & $\mathbf{Y}_{\text {desorption }}^{\text {acetate }}(\%)$ & $\mathbf{Y}_{\text {desorption }}^{\text {butyrate }}(\%)$ & $\mathbf{Y}_{\text {desorption }}^{\text {caproate }}(\%)$ \\
\hline \multirow{2}{*}{ a Temperature $\left({ }^{\circ} \mathrm{C}\right)$} & 5 & $88.10 \pm 0.36$ & $81.66 \pm 0.33$ & $65.79 \pm 0.49$ \\
& 20 & $96.90 \pm 0.29$ & $87.74 \pm 0.21$ & $89.04 \pm 0.12$ \\
& 30 & $95.05 \pm 0.23$ & $86.75 \pm 0.29$ & $88.25 \pm 0.29$ \\
${ }^{b} \mathrm{NaOH}$ concentration $(\mathrm{M})$ & 40 & $95.17 \pm 0.19$ & $86.12 \pm 0.22$ & $88.18 \pm 0.13$ \\
\hline & 0.5 & $85.20 \pm 0.10$ & $80.17 \pm 0.09$ & $78.65 \pm 0.32$ \\
& 1.5 & $99.84 \pm 0.16$ & $94.75 \pm 0.13$ & $95.74 \pm 0.12$ \\
& 2.0 & $99.80 \pm 0.26$ & $95.01 \pm 0.33$ & $95.94 \pm 0.21$ \\
& 2.5 & $99.71 \pm 0.35$ & $97.30 \pm 0.16$ & $96.12 \pm 0.20$ \\
\hline
\end{tabular}

a The experiments were conducted at the eluent concentration of $1 \mathrm{M} \mathrm{NaOH} .{ }^{\mathrm{b}}$ The elutions were carried out at $30^{\circ} \mathrm{C} .{ }^{\mathrm{c}}$ The desorption efficiency was calculated using Equation (4), as described in the text. Every test was done in triplicate. The results represent averages and standard deviation. 
Increasing $\mathrm{NaOH}$ concentration from 0.5 to $1.5 \mathrm{M}$ could enhance the desorption capacity up to $10.77 \pm 0.28 \mathrm{mg} / \mathrm{g}$ (Table 2). The desorption capacity of caproate significantly increased from $78.65 \% \pm 0.32 \%$ to $95.74 \% \pm 0.12 \%(p<0.01)$. The increased eluent $\mathrm{NaOH}$ concentration from 1.5 to $2.5 \mathrm{M}$ did not increase the desorption efficiency of caproate significantly $(p>0.05)$, as the increment was less than $0.4 \%$. With these findings, we decided the optimal eluent concentration at $1.5 \mathrm{M} \mathrm{NaOH}$.

In the reusability test for resin D201, its adsorption capacity and desorption efficiency were measured during eight adsorption-desorption cycles under the optimal elution conditions. The results of the 2nd, 4th, 6th, and 8th cycles are addressed in Figure 4 . The adsorption capacity and desorption efficiency of caproate from the resin fell slightly after eight cycles of the test and these two parameters in the 8 th cycle were $59.10 \pm 2.27 \mathrm{mg} / \mathrm{g}$ and $93.4 \% \pm 2.8 \%$, respectively. The results in the 8 th cycle showed no significant difference $(p>0.05)$ to those measured in the previous cycles, which suggested that the resin was reusable.

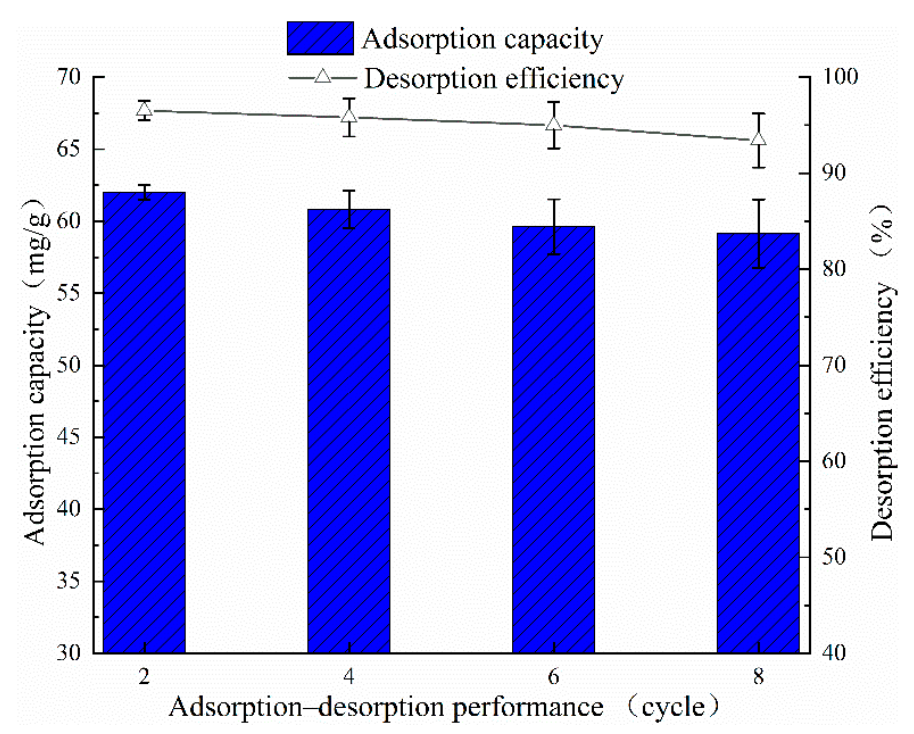

Figure 4. Reusability of resin D201 for caproate production. The adsorption and desorption of caproate versus resin were measured over eight performance cycles using the simulation broth. The results are averages and standard deviations of three parallel experiments.

\subsection{Enhanced Caproate Fermentation with Anion Exchange}

The anion-exchange resin D201 showed a relatively reliable performance when using the simulated fermentation broth. The resin was then coupled with the caproate fermentation. As shown in Figure 5, from the start to the 67th day (Phase 1), two bioreactors (the control and adsorption groups) were operated in parallel. The fermentation performance of the two bioreactors was similar. The ethanol consumption rate of both reactors was $89.7 \% \pm 2.3 \%$ and their acetate consumption rate was $73.3 \% \pm 0.1 \%$. The maximum caproate concentration after 67 days was $11.2 \pm 0.3 \mathrm{~g} / \mathrm{L}$. In Phase 1 , the average $(0.16 \pm 0.01 \mathrm{~g}$-caproate/L/d) and maximum $(0.57 \pm 0.03 \mathrm{~g}$-caproate/L/d) caproate production rates of both reactors were similar. 


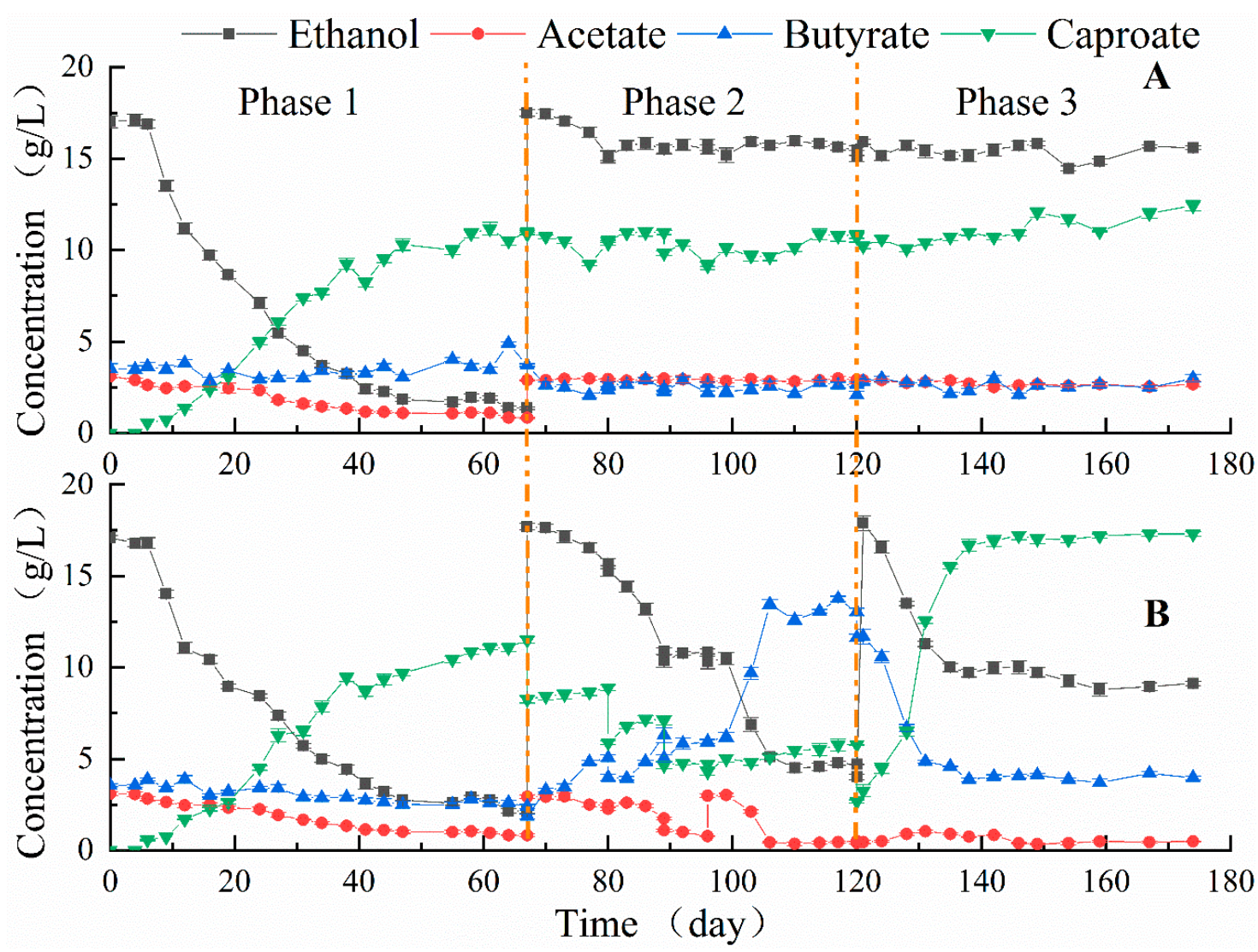

Figure 5. Concentration dynamics of carboxylates during caproate fermentation using anion-exchange resin. Two experimental sets were carried out, including (A) the control and (B) the adsorption groups. The fermentation period was divided into three phases. In Phase 1, both groups exhibited the same dynamics. In Phase 2, ethanol and acetate were supplied, and the adsorption was carried out on the 67 th, the 81 st, the 89 th, and the 120th days in (B). In Phase 3, although the large volume of caproate was removed in Phase 2, the concentration of caproate rose up exponentially. The results are averages of triplicate measurements.

After Phase 1, on the 67th day, ethanol was supplied as an electron donor in both reactors. However, the utilization of ethanol in the control group (Figure 5A) was severely constrained by caproate feedback inhibition. The net ethanol consumption within Phase 2 and Phase 3 (from the 67th day to the 174 th day) was no more than $11.3 \%$. As ethanol utilization is the first step in caproate fermentation, this inevitable occurrence leads to a poor caproate production performance. The net caproate production was $1.44 \pm 0.21 \mathrm{~g} / \mathrm{L}$ and the final caproate concentration was $12.43 \pm 0.29 \mathrm{~g} / \mathrm{L}$. In order to improve caproate production, caproate separation was necessary.

For the adsorption group (Figure $5 \mathrm{~B}$ ), the anion-exchange operation reduced caproate concentration in a stepwise manner from $11.50 \pm 0.19$ to $4.66 \pm 0.20 \mathrm{~g} / \mathrm{L}$ in Phase 2. Accordingly, ethanol consumption increased significantly and the chain elongation performance recovered gradually. The ethanol consumption rate reached $77.4 \%$ and the average caproate production rate between the 80 th day and the 89 th day increased to $0.14 \pm 0.01$ g-caproate $/ \mathrm{L} / \mathrm{d}$, which was at the same level of the control group in Phase 1. However, this increase in caproate production was insufficient and unstable. The highest caproate production rate, namely $0.3 \mathrm{~g}$ caproate/L/d, was only half of the caproate production rate of the control group $(0.60 \pm 0.01 \mathrm{~g} / \mathrm{L} / \mathrm{d})$ in Phase 1 and the highest caproate accumulation concentration was less than $8.91 \pm 0.17 \mathrm{~g} / \mathrm{L}$. Butyrate accumulation began in Phase 2. Butyrate became the main product between the 103rd and the 120th days and its concentration reached a maximum of $13.74 \pm 0.15 \mathrm{~g} / \mathrm{L}$ on the 117th day. It has been reported that butyrate is an insufficient chain elongation product in caproate fermentation and its accumulation has been attributed to caproate feedback inhibition and low ethanol 
supply [32,33]. Even though butyrate uptake is involved in the chain elongation process, butyrate is a less favored substrate for the chain elongate microbiome. Thus, further ethanol supply and anion exchange took place on the 120th day.

In Phase 3, the ethanol to acid ratio was readjusted from 0.65 to 3.50 (as $\mathrm{mol} / \mathrm{mol}$ ) and the caproate concentration was reduced to $2.67 \pm 0.09 \mathrm{~g} / \mathrm{L}$ on the 120 th day. With sufficient ethanol supply and a low caproate concentration, the caproate production performance was finally regained. A maximum caproate concentration of $17.30 \pm 0.13 \mathrm{~g} / \mathrm{L}$ was obtained, which was $42.2 \%$ higher than that of the control group. The average (from the 120th to the 142nd days) and the maximum caproate production rates were $0.64 \pm 0.01 \mathrm{~g}$-caproate/L/d and $2.03 \pm 0.02$ g-caproate/ $/ \mathrm{d}$, respectively, which were $276 \%$ and $238 \%$ higher than those in the control group, respectively. The butyrate accumulated in Phase 2 was sufficiently utilized. Overall, cumulative caproate production in the adsorption group was $29.10 \pm 0.33 \mathrm{~g} / \mathrm{L} \cdot \mathrm{broth}$, which was $134 \%$ higher than that of the control group. An enhancement in performance was thus achieved in the adsorption group.

The adsorption and desorption performances of the anion-exchange resin D201 with the actual fermentation broth were evaluated. The performances listed in Table 3 showed that $\mathrm{Q}_{\text {caproate }}$ was maintained above $50 \mathrm{mg} / \mathrm{g}$, which was above the minimum capacity required for resin application [29]. Meanwhile, the $R_{s}$ values of the D201 dropped to 1.90-4.62, which were lower than those measured in the experiments with the simulation broth. This result might be due to the relatively high concentration of acetate and butyrate in the actual fermentation broth, which has been shown to increase the competitive adsorption [30]. However, $Q_{\text {caproate }}$ was still higher than $\mathrm{Q}_{\text {butyrate }}$ or $\mathrm{Q}_{\text {acetate }}$ in the actual fermentation broth, even when the concentration of butyrate was higher than that of caproate. This finding suggested that caproate had higher affinity. Additionally, the desorption efficiency in the actual fermentation broth was maintained at a similar level to that in the simulated one, which was no less than $93 \%$.

Table 3. Adsorption-desorption performance of carboxylates during anion-exchange resin production of caproate using the actual fermentation broth.

\begin{tabular}{ccccc}
\hline Adsorption/Desorption Operation & $\begin{array}{c}{ }^{\mathbf{a}} \mathbf{Q} \text { acetate } \\
(\mathbf{m g} / \mathbf{g})\end{array}$ & $\begin{array}{c}\mathbf{Q}_{\text {butyrate }} \\
\text { (mg/g) }\end{array}$ & $\begin{array}{c}\mathbf{Q}_{\text {caproate }} \\
\text { (mg/g) }\end{array}$ & $\begin{array}{c}\text { Desorption } \\
\text { Efficiency (\%) }\end{array}$ \\
\hline The first operation at the 67th day & $2.13 \pm 0.02$ & $10.87 \pm 0.09$ & $60.17 \pm 0.17$ & $93.4 \pm 0.27$ \\
The second operation at the 80th day & $4.13 \pm 0.07$ & $15.46 \pm 0.10$ & $59.36 \pm 0.31$ & $94.0 \pm 0.31$ \\
The third operation at the 89th day & $3.60 \pm 0.03$ & $19.24 \pm 0.29$ & $56.99 \pm 0.29$ & $95.1 \pm 0.22$ \\
The fourth operation at the 120th day & $0.74 \pm 0.02$ & $28.25 \pm 0.23$ & $55.13 \pm 0.25$ & $93.5 \pm 0.13$ \\
\hline
\end{tabular}

${ }^{a} Q_{\text {acetate}}, Q_{\text {butyrate, }}$ and $Q_{\text {caproate }}$ are the adsorption capacities to the corresponding compounds, which were defined using Equation (1). The results are the averages and standard deviations of the triplicate measurements.

\section{Conclusions}

In this study, enhanced caproate production performance was achieved by applying anion-exchange resin to mixed culture-caproate fermentation. In the resin comparison, the strongly basic anion-exchange resin showed better potential to enhance caproate production and D201 was the optimal resin among the test resins due to its higher adsorption, selectivity, and desorption performance. The resin D201 also maintained a stable performance during eight adsorption-desorption cycles. In the enhancement of caproate fermentation using the adsorption process with caproate removal and sufficient ethanol supply, the average and maximum production rates of caproate increased to $0.64 \pm 0.02$ g-caproate/L/d and $2.03 \pm 0.02$ g-caproate/L/d, respectively, which were $276 \%$ and $238 \%$ higher than those in the control group, respectively. The highest caproate concentration was $17.30 \pm 0.13 \mathrm{~g} / \mathrm{L}$ and the cumulative caproate production was $29.10 \pm 0.33 \mathrm{~g} / \mathrm{L} \cdot \mathrm{broth}$, which were $39.2 \%$ and $134 \%$ higher than those in the control group, respectively. Furthermore, the adsorption-desorption performance of the resin D201 was similar for the actual fermentation broth compared to the simulated one. Although more acetate and butyrate remained in the medium and competitive adsorption increased, the adsorption affinity of caproate to resin was still high. With our findings, the application 
of anion-exchange resin could be a practical approach to enhance anaerobic mixed culture fermentation for caproate production.

Author Contributions: Conceptualization, J.Y. and Z.H.; formal analysis, W.R.; funding acquisition, Z.H.; methodology, C.L.; resources, M.Z.; software, J.L.; validation, Z.H., P.W., and C.L.; writing—original draft, C.L.; writing-review and editing, J.Y.

Funding: This research was funded by the National Natural Science Foundation of China (NSFC21506076, NSFC51678279), the Fundamental Research Funds for the Central Universities (JUSRP51918A, JUSRP51903B).

Acknowledgments: The authors acknowledge the financial support from the National Natural Science Foundation of China (NSFC21506076, NSFC51678279), the Fundamental Research Funds for the Central Universities (JUSRP51918A, JUSRP51903B), the National Key Research and Development Program of China (2018YFC1903002).

Conflicts of Interest: The authors declare no conflict of interest.

\section{References}

1. $\quad \mathrm{Xu}$, J.; Guzman, J.J.L.; Andersen, S.J.; Korneel, R.; Angenent, L.T. In-line and selective phase separation of medium-chain carboxylic acids using membrane electrolysis. Chem. Commun. 2015, 51, 6847-6850. [CrossRef] [PubMed]

2. Angenent, L.T.; Richter, H.; Buckel, W.; Spirito, C.M.; Steinbusch, K.J.; Plugge, C.M.; Strik, D.P.; Grootscholten, T.I.; Buisman, C.J.; Hamelers, H.V. Chain elongation with reactor microbiomes: Open-culture biotechnology to produce biochemicals. Environ. Sci. Technol. 2016, 50, 2796-2810. [CrossRef] [PubMed]

3. Agler, M.T.; Spirito, C.M.; Usack, J.G.; Werner, J.J.; Angenent, L.T. Chain elongation with reactor microbiomes: Upgrading dilute ethanol to medium-chain carboxylates. Energy Environ. Sci. 2012, 5, 8189. [CrossRef]

4. Chen, W.S.; Strik, D.; Buisman, C.J.N.; Kroeze, C. Production of caproic acid from mixed organic waste: An environmental life cycle perspective. Environ. Sci. Technol. 2017, 51, 7159-7168. [CrossRef] [PubMed]

5. Grootscholten, T.I.; Steinbusch, K.J.; Hamelers, H.V.; Buisman, C.J. Chain elongation of acetate and ethanol in an upflow anaerobic filter for high rate MCFA production. Bioresour. Technol. 2013, 135, 440-445. [CrossRef]

6. Grootscholten, T.I.M.; Strik, D.P.B.T.B.; Steinbusch, K.J.J.; Buisman, C.J.N.; Hamelers, H.V.M. Two-stage medium chain fatty acid (MCFA) production from municipal solid waste and ethanol. Appl. Energy 2014, 116, 223-229. [CrossRef]

7. Steinbusch, K.J.J.; Hamelers, H.V.M.; Plugge, C.M.; Buisman, C.J.N. Biological formation of caproate and caprylate from acetate: Fuel and chemical production from low grade biomass. Energy Environ. Sci. 2011, 4, 216-224. [CrossRef]

8. Steven, V.G.; Logan, B.E. Inhibition of biohydrogen production by undissociated acetic and butyric acids. Environ. Sci. Technol. 2005, 39, 9351.

9. Roghair, M.; Liu, Y.; Adiatma, J.C.; Weusthuis, R.A.; Bruins, M.E.; Buisman, C.J.N.; Strik, D. Effect of n-caproate concentration on chain elongation and competing processes. ACS Sustain. Chem. Eng. 2018, 6, 7499-7506. [CrossRef]

10. Roddick, F.A.; Britz, M.L. Production of hexanoic acid by free and immobilised cells of megasphaera elsdenii: Influence of in-situ product removal using ion exchange resin. J. Chem. Technol. Biotechnol. 2015, 69, 383-391. [CrossRef]

11. Liu, Y.; He, P.; Shao, L.; Zhang, H.; Lu, F. Significant enhancement by biochar of caproate production via chain elongation. Water Res. 2017, 119, 150-159. [CrossRef] [PubMed]

12. Roghair, M.; Strik, D.P.B.T.B.; Steinbusch, K.J.J.; Weusthuis, R.A.; Bruins, M.E.; Buisman, C.J.N. Granular sludge formation and characterization in a chain elongation process. Process Biochem. 2016, 51, 1594-1598. [CrossRef]

13. Choi, K.; Jeon, B.S.; Kim, B.C.; Oh, M.K.; Um, Y.; Sang, B.I. In situ biphasic extractive fermentation for hexanoic acid production from sucrose by Megasphaera elsdenii NCIMB 702410. Appl. Biochem. Biotechnol. 2013, 171, 1094-1107. [CrossRef] [PubMed]

14. de Cavalcante, W.A.; Leitão, R.C.; Gehring, T.A.; Angenent, L.T.; Santaella, S.T. Anaerobic fermentation for n-caproic acid production: A review. Process Biochem. 2017, 54, 106-119. [CrossRef]

15. Huang, C.; Xu, T.; Zhang, Y.; Xue, Y.; Chen, G. Application of electrodialysis to the production of organic acids: State-of-the-art and recent developments. J. Membrane Sci. 2007, 288, 1-12. [CrossRef] 
16. da Silva, A.H.; Miranda, E.A. Adsorption/desorption of organic acids onto different adsorbents for their recovery from fermentation broths. J. Chem. Eng. Data 2013, 58, 1454-1463. [CrossRef]

17. Jones, J.; Lee, C.H.; Wang, J.; Poenie, M. Use of anion exchange resins for one-step processing of algae from harvest to biofuel. Energies 2012, 5, 2608. [CrossRef]

18. Pradhan, N.; Rene, E.R.; Lens, P.N.L.; Dipasquale, L.; D’Ippolito, G.; Fontana, A.; Panico, A.; Esposito, G. Adsorption behaviour of lactic acid on granular activated carbon and anionic resins: Thermodynamics, isotherms and kinetic studies. Energies 2017, 10, 665. [CrossRef]

19. Ge, S.; Usack, J.G.; Spirito, C.M.; Angenent, L.T. Long-term n-caproic acid production from yeast-fermentation beer in an anaerobic bioreactor with continuous product extraction. Environ. Sci. Technol. 2015, 49, 8012-8021. [CrossRef]

20. Xu, J.; Hao, J.; Guzman, J.J.L.; Spirito, C.M.; Harroff, L.A.; Angenent, L.T. Temperature-phased conversion of acid whey waste into medium-chain carboxylic acids via lactic acid: No external e-Donor. Joule 2018, 2, 280-295. [CrossRef]

21. Moon, P.J.; Parulekar, S.J.; Tsai, S.P. Competitive anion transport in desalting of mixtures of organic acids by batch electrodialysis. J. Membrane Sci. 1998, 141, 75-89. [CrossRef]

22. Arslan, D.; Zhang, Y.; Steinbusch, K.J.J.; Diels, L.; Hamelers, H.V.M.; Buisman, C.J.N.; De Wever, H. In-situ carboxylate recovery and simultaneous $\mathrm{pH}$ control with tailor-configured bipolar membrane electrodialysis during continuous mixed culture fermentation. Sep. Purif. Technol. 2017, 175, 27-35. [CrossRef]

23. Kanazawa, N.; Urano, K.; Kokado, N.; Urushigawa, Y. Adsorption equilibrium equation of carboxylic acids on anion-exchange resins in water. J. Collid. Interf. Sci. 2001, 238, 196-202. [CrossRef]

24. Kammerer, J.; Carle, R.; Kammerer, D.R. Adsorption and ion exchange: Basic principles and their application in food processing. J. Agric. Food Chem. 2011, 59, 22-42. [CrossRef] [PubMed]

25. Rebecchi, S.; Pinelli, D.; Bertin, L.; Zama, F.; Fava, F.; Frascari, D. Volatile fatty acids recovery from the effluent of an acidogenic digestion process fed with grape pomace by adsorption on ion exchange resins. Chem. Eng. J. 2016, 306, 629-639. [CrossRef]

26. Fargues, C.; Lewandowski, R.; Lameloise, M.L. Evaluation of ion-exchange and adsorbent resins for the detoxification of beet distillery effluents. Ind. Eng. Chem. Res. 2010, 49, 377-379. [CrossRef]

27. APHA. Standard Methods for the Examination of Water and Wastewater; APHA: Washington, DC, USA, 2005; ISBN 9780875530475.

28. Khor, W.C. Production of Lactic Acid and Derivatives from Grass Using Mixed Populations. Ph.D. Thesis, Ghent University, Ghent, Belgium, 2017.

29. Lopez-Garzon, C.S.; Straathof, A.J. Recovery of carboxylic acids produced by fermentation. Biotechnol. Adv. 2014, 32, 873-904. [CrossRef] [PubMed]

30. Chu, B.; Whitney, D.C.; Diamond, R.M. On anion-exchange resin selectivities. J. Inorg. Nucl. Chem. 1962, 24, 1405-1415. [CrossRef]

31. Gluszcz, P.; Jamroz, T.; Sencio, B.; Ledakowicz, S. Equilibrium and dynamic investigations of organic acids adsorption onto ion-exchange resins. Bioprocess Biosyst. Eng. 2004, 26, 185-190.

32. Lonkar, S.; Fu, Z.; Holtzapple, M. Optimum alcohol concentration for chain elongation in mixed-culture fermentation of cellulosic substrate. Biotechnol. Bioeng. 2016, 113, 2597-2604. [CrossRef]

33. Weimer, P.J.; Stevenson, D.M. Isolation, characterization, and quantification of Clostridium kluyveri from the bovine rumen. Appl. Microbiol. Biotechnol. 2012, 94, 461-466. [CrossRef] [PubMed]

(C) 2019 by the authors. Licensee MDPI, Basel, Switzerland. This article is an open access article distributed under the terms and conditions of the Creative Commons Attribution (CC BY) license (http://creativecommons.org/licenses/by/4.0/). 